\section{Purpura on the truncus and extremities}

\section{CLINICAL INTRODUCTION}

A 36-year-old woman with Down's syndrome and spleen hypoplasia presented with a fever of $40^{\circ} \mathrm{C}$ lasting for $12 \mathrm{~h}$. She had taken $1 \mathrm{mg}$ prednisolone/day for mild graft-versus-host disease after allogeneic stem cell transplantation 4 years previously. Her BP was 91/44 mm Hg, HR 110 beats/min and RR 30 breaths/

For the answer see page 199 min. Her heart sound, lung sound and skin appearance were unremarkable. Laboratory findings showed leucocytosis $\left(13.12 \times 10^{9} / \mathrm{L}\right)$ and normal platelet count $\left(269 \times 10^{9} / \mathrm{L}\right)$. She was discharged home, but $16 \mathrm{~h}$ after fever onset, experienced cardiopulmonary arrest.

\section{QUESTION}

What does the image show?

A. Henoch-Schönlein purpura

B. Steroid purpura

C. Postmortem lividity

D. Purpura fulminans 


\section{Purpura on the truncus and extremities}

From the question on page 174

\section{ANSWER: D}

DIAGNOSIS: acute infectious purpura fluminans (PF) caused by Streptococcus pneumoniae.

Figure 1 shows systemic impalpable purpura that rapidly emerged on the patient's truncus gravity-independently. Gram staining of her peripheral blood revealed gram-positive diplococci (figure 2, arrows), indicative of acute infectious PF caused by $S$. pneumoniae. Despite strenuous resuscitation and broadspectrum antibiotic administration, she died. Her blood culture results subsequently tested positive for $S$. pneumoniae.

$\mathrm{PF}$ is a rare, fatal syndrome accompanied by skin necrosis and disseminated intravascular coagulation, caused by protein C-deficiency or overwhelming sepsis, ${ }^{1}$ typically caused by Neisseria meningitidis and S. pneumoniae. ${ }^{2}$ This patient had hyposplenia, a risk factor for invasive N. meningitidis and S. pneumoniae infection. ${ }^{3}$ Systemic purpura and a rapid, progressive clinical course is indicative of PF, but obtaining blood culture results to confirm infection requires several days. Gram staining of a peripheral blood sample may be useful for identifying causative bacteria, guiding an early decision to use empirical antibiotics.

Henoch-Schönlein purpura is rare and usually benign in adults, and is typically characterised by elevated palpable purpura and abdominal pain. Long-term corticosteroid administration causes steroid purpura, but never causes cardiopulmonary arrest (CPA). Postmortem lividity generally appears $15 \mathrm{~h}$ after death; this patient was immediately taken to the hospital upon CPA; therefore, postmortem lividity was not a consideration.

\section{Ryutaro Tanizaki, ${ }^{1}$ Masaki Oya, ${ }^{2}$ Yousuke Takemura ${ }^{3}$}

${ }^{1}$ Department of Community Medicine, IGA, Mie University Graduate School of Medicine, Tsu-city, Mie, Japan

${ }^{2}$ General Medicine, Nabari City Hospital, Nabari-city, Mie, Japan

${ }^{3}$ Department of Family Medicine, Mie University School of Medicine and Graduate School of Medicine, Tsu-city, Mie, Japan

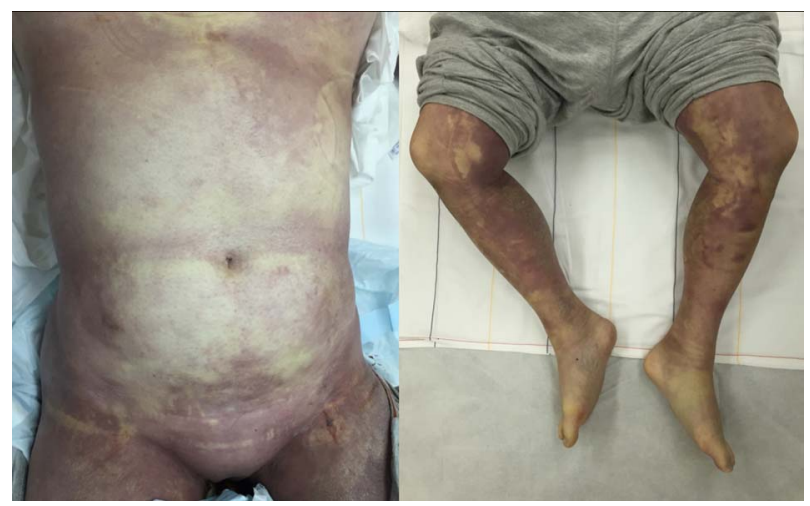

Figure 1 The patient's appearance on readmission.

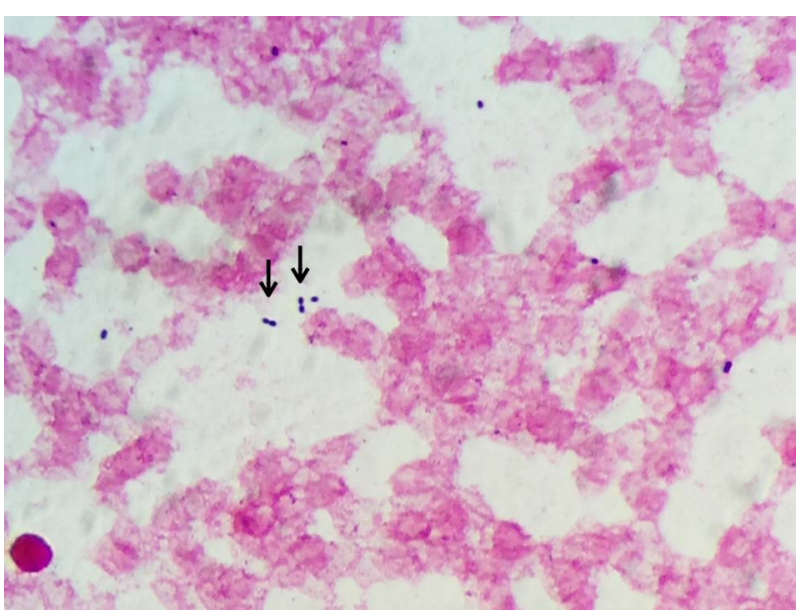

Figure 2 Gram-stained sample of the patient's peripheral blood. The arrows suggest typical gram positive diplococci.

Correspondence to Dr Ryutaro Tanizaki, General Medicine, Nabari City Hospital, West 1st-178, Yurigaoka, Nabari-city, Mie 518-0481, Japan; rtanizak20@clin.medic. mie-u.ac.jp

Contributors RT and MO wrote this paper. YT supervised it.

Competing interests None declared.

Patient consent Obtained.

Provenance and peer review Not commissioned; internally peer reviewed.

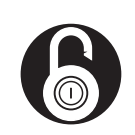

\section{OPEN ACCESS}

Open Access This is an Open Access article distributed in accordance with the Creative Commons Attribution Non Commercial (CC BY-NC 4.0) license, which permits others to distribute, remix, adapt, build upon this work non-commercially, and license their derivative works on different terms, provided the original work is properly cited and the use is non-commercial. See: http://creativecommons.org/ licenses/by-nc/4.0/

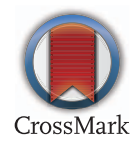

To cite Tanizaki R, Oya M, Takemura Y. Emerg Med J 2017;34:199.

Received 3 October 2016

Emerg Med J 2017;34:199.

doi:10.1136/emermed-2016-205777

\section{REFERENCES}

1 Lerolle N, Carlotti A, Melican K, et al. Assessment of the interplay between blood and skin vascular abnormalities in adult purpura fulminans. Am J Respir Crit Care Med 2013;188:684-92.

2 Levin M, Eley BS, Louis J, et al. Postinfectious purpura fulminants caused by an autoantibody directed against protein S. J Pediatr 1995;127:355-63.

3 Di Sabatino A, Carsetti R, Corazza GR. Post-splenectomy and hyposplenic states. Lancet 2011;378:86-97. 